\title{
REPRESENTAÇÕES SOCIAIS NOS QUADRINHOS DE MAURÍCIO DE SOUSA
}

\author{
Neide Nunes Rodrigues* \\ Mônica Santos de Souza Melo**
}

Resumo: Neste artigo focalizamos o gênero histórias em quadrinhos, que é tratado sob a perspectiva da Teoria das Representações Sociais (MOSCOVICI, 2007; GUARESCHI e JOVCHELOVITHC, 2002; DUVEEN, 2007) associadas à Análise do Discurso (CHARAUDEAU, 2008). Nosso corpus se constitui de seis exemplares da Turma da Mônica e de outros seis da Turma da Mônica Jovem de Maurício de Sousa Produções. Tínhamos como objetivo identificar as representações do público infanto-juvenil nelas veiculadas. Verificamos imaginários sócio-discursivos relacionados à natureza, ao uso de tecnologias, à amizade, à relação pais e filhos e à relação homem e mulher, o que confirma que essas narrativas não apenas contam uma história, como também são veículos de valores, crenças e ideologias da sociedade onde circulam.

Palavras-chave: Análise do discurso. Representações sociais. Histórias em quadrinhos.

\begin{abstract}
In this article, we study the genre comic strips which are investigated according to a Social Representations theory (MOSCOVICI, 2007; GUARESCHI and JOVCHELOVITHC, 2002; DUVEEN, 2007), and to a Discourse Analyses theoretical framework (CHARAUDEAU, 2008). Our corpus is constituted by six Mauricio de Sousa Produções' magazines of Turma da Mônica and by six of Turma da Mônica Jovem. We aimed at identifying the social representations of children and young people in the magazines. We found social discursive representations of the nature, the use of technology, friendship, relationship among parents and their kids, and relationship between man and woman. Our results confirm these narratives not only tell stories, but they also represent values, beliefs, ideologies of the society where they are distributed.
\end{abstract}

Keywords: Discourse Analysis. Social representations. Comic books.

\section{Introdução}

As histórias em quadrinhos são uma forma de narrativa que emprega recursos linguísticos e imagéticos para narrar uma história. Como outras formas de narrativa, elas veiculam ideias, informações, saberes, hábitos, costumes, normas, valores culturais e representações sociais de

\footnotetext{
* Mestranda em Estudos Linguísticos. Universidade Federal de Viçosa. Contato: neidenrodrigues@yahoo.com.br

**Doutora em Estudos Linguísticos. Universidade Federal de Minas Gerais. Contato: monicassmelo@yahoo.com.br
} 
uma determinada cultura. Encaradas como meio de expressão da realidade histórica e social, elas são fontes que nos possibilitam identificar imaginários sociais de um dado grupo social.

Nosso corpus se constitui de seis exemplares da revista em quadrinhos da Turma da Mônica e dos seis primeiros números da Turma da Mônica Jovem de Maurício de Sousa ${ }^{1}$. A primeira, criada em 1959, se destina ao público infantil e a segunda se encontra em circulação desde setembro de 2008, tendo como público-alvo os adolescentes. Esta revista apresenta os mesmos personagens da revista infantil, porém como adolescentes. No entanto, os desenhos são mais sofisticados e incorporam muitos traços do estilo mangá.

Compreendidas sob a perspectiva semiolinguística do discurso, as histórias em quadrinhos são entendidas como um evento de produção e interpretação. Como tal, a comunicação entre aquele que produz um texto e o outro que o recebe e interpreta depende "dos saberes supostos que circulam entre os protagonistas da linguagem" (CHARAUDEAU, 2008). O que significa dizer que o leitor atribui sentido ao que é narrado e representado nas histórias, acionando um conjunto de representações sociais. Elas são construídas e adquiridas através do convívio em uma determinada comunidade social e do partilhar com seus membros de diferentes experiências, como, físicas, intelectuais, e afetivas.

Empregamos a Teoria das Representações Sociais como instrumento de análise para o nosso corpus por entender que o estudo das representações sociais subjacentes aos textos produzidos por uma dada sociedade tornase importante na medida em que nos permite investigar e identificar os imaginários sociais que circulam dentro de um grupo, situado histórico e culturalmente. As representações sociais servem como instrumento para orientar as práticas sociais e interpretar os acontecimentos da realidade cotidiana.

A análise das revistas que retratam os mesmos personagens em duas fases, infância e adolescência, torna possível a identificação e a compreensão da transição por que passam os adolescentes, que resulta em transformações

\footnotetext{
${ }^{1}$ Doravante entenda-se que nome pessoal "Maurício de Sousa ou o termo "autor" e possíveis variações se referem a toda equipe responsável pela produção das revistas Turma da Mônica e Turma da Mônica Jovem.
} 
físicas e psicológicas. O desenvolvimento dos indivíduos reflete-se também no modo como ele passa a conceber a realidade a sua volta e a interagir com os outros, criando novas formas de vínculos sociais e afetivos.

Neste artigo apresentamos um estudo sobre o universo infantojuvenil, representado através do estrato linguístico e icônico nas revistas da Turma da Mônica e Turma da Mônica Jovem.

\section{Quadrinhos e Mangás}

As histórias em quadrinhos são narrativas compostas por uma sequência justaposta de quadros que visam contar uma história. Apresentando diferentes recursos de linguagem, seja por meio do texto verbal, seja pelo icônico, essas histórias vem conquistando um público variado desde seu surgimento. Como outros veículos de informação e entretenimento, elas vêm contribuindo para disseminação e sedimentação de valores e crenças de uma determinada sociedade.

Os mangás, por sua vez, também são histórias narradas a partir de quadros sequencialmente justapostos. No entanto, eles constituem histórias em quadrinhos em estilo japonês e apresentam algumas diferenças em relação aos quadrinhos ocidentais. Enquanto nestes predomina uma disposição horizontal, naqueles, quadros justapostos e de dimensões variadas compõem o espaço da página. Personagens, onomatopéias e demais recursos também se sobrepõem e constituem uma diagramação complexa na estruturação da história.

No que diz respeito ao aspecto gráfico, os mangás são geralmente impressos em preto e branco, as histórias são lidas de trás para frente e os personagens são ilustrados com expressões faciais realçadas, como por exemplo, o tamanho exagerado dos olhos.

Com relação à temática, esse estilo de histórias é conhecido por enfocar aspectos cotidianos e temas da vida familiar, como namoro, amizade, vida escolar, trabalho, dentre outros. Os personagens, geralmente, expressam com maior freqüência suas emoções e sentimentos, ao mesmo tempo em que representam os valores vigentes e socialmente aceitos dentro da cultura em que são produzidos.

Segundo Melo e Rodrigues (2010, p. 160), a mídia, ao veicular representações sociais, não só reflete comportamentos sociais como também é capaz de remodelá-los. De acordo com esse ponto de vista, as 
histórias em quadrinhos e os mangás podem ser compreendidas como suporte, linguístico e visual, à veiculação de discursos de representação, pela disseminação de valores, crenças e normas de um grupo.

\section{Teoria das Representações Sociais}

Moscovici desenvolveu na França, no início da década de 60, a teoria das Representações Sociais (RS) numa tentativa de construir uma psicologia social do conhecimento. Esse ramo da psicologia se ocupada "dos processos através do quais o conhecimento é gerado, transformado e projetado no mundo social" (DUVEEN, 2007, p. 9) através da interação e da comunicação entre os sujeitos sociais.

As representações podem, assim, ser consideradas fenômenos sociais e psicológicos que se constroem a partir da vida coletiva e nos permitem, por isso, identificar saberes, ideologias e crenças populares. Como fenômeno social, elas são formadas "quando as pessoas se encontram para falar, argumentar, discutir o cotidiano, ou quando elas estão expostas às instituições, aos meios de comunicação, aos mitos e à herança histórico cultural de suas sociedades" (GUARESCHI e JOVCHELOVITCH, 2002, p. 20). São, portanto, formas de construção social da linguagem. Ao compartilhar esses conhecimentos, o sujeito desenvolve uma identidade própria, e ao mesmo tempo social, num processo de internalização de características de sua comunidade, e cria símbolos que ele organiza em discurso para interagir com os demais a sua volta.

Nessa perspectiva, Melo (2003) propõe "que os processos que engendram representações sociais estão inseridos na comunicação e nas práticas sociais, como o diálogo, o discurso, rituais, padrões de trabalho e produção, arte, em síntese, cultura" (p. 152).

As trocas sociais, dessa forma, estruturadas e organizadas em forma de discurso, permitem aos indivíduos construir, elaborar e compartilhar as representações sociais do cotidiano, que constituem o que se denomina 'senso comum'.

Para Minayo (1995, apud MELO, 2003, p. 251), o senso comum trata-se de conjuntos de abstrações sociais do cotidiano, formalizações e generalizações, construídas e interpretadas a partir das experiências do dia-a-dia, ou seja, elas representam o que teorias recentes consideram protótipos de fenômenos sociais (MOSCOVICI, 2007). Em outras palavras, 
"as representações sustentadas pelas influências sociais da comunicação constituem as realidades de nossas vidas cotidianas e servem como o principal meio para estabelecer as associações com as quais nós nos ligamos uns aos outros" (DUVEEN, 2007, p. 8).

Assim, o discurso produzido por um sujeito, inserido em uma dada cultura e pertencente a um grupo social, veicula representações coletivas, assim como revela sistemas de valores, normas, hábitos e costumes de seu meio sócio-hitórico. No entanto, como a linguagem não é neutra, a difusão de determinadas representações sociais revela também o posicionamento do sujeito falante frente às questões abordadas e discutidas por ele.

As diferentes formas de discurso são determinadas não só por condições sociais, culturais e históricas. Além de questões políticas e econômicas, as relações de produção e interpretação dos textos influenciam também a estruturação dos diferentes discursos. Segundo Oliveira (2009, p. 107), estudar as representações sociais é buscar conhecer a maneira como um grupo humano constrói um conjunto de saberes que expressam a identidade de um grupo social.

Dessa forma, as histórias em quadrinhos da Turma da Mônica e Turma da Mônica Jovem, ao definirem dois públicos-alvos distintos, sugerem uma adaptação no nível discursivo para retratar e divulgar ao leitor certas representações sociais.

\section{As representações sociais nos quadrinhos}

As histórias em quadrinhos, enquanto forma de comunicação e mediação social, podem ser usadas para ensinar comportamentos dentro da comunidade, propagar ideias, discutir valores, dramatizar relações sociais e os problemas de convívio (cf. EISNER, 2008, p. 11). Elas veiculam, pois, representações sociais de uma sociedade, que embora pertença a todos, transcende a cada um individualmente; refletem hábitos, costumes, crenças e valores construídos e compartilhados por um grupo. Para Jovchelovitch (2002, p. 82), as representações sociais emergem desse modo como processo que ao mesmo tempo desafia e reproduz, repete e supera, que é formado, mas que também forma a vida de uma comunidade. No entanto, para que isso aconteça, os sujeitos precisam ter um conhecimento comum de um sistema de símbolos, que lhes permita compreender o discurso daquele que o produz. 
Jovchelovitch (2002, p. 71) argumenta que os símbolos são importantes para a teoria das representações sociais porque eles podem evocar presença apesar da ausência, uma vez que eles têm a função de criar o objeto representado. Eles possibilitam o reconhecimento por parte dos indivíduos de uma realidade compartilhada, ou o que a autora chama de realidade dos Outros.

Nas histórias em quadrinhos, a codificação simbólica é construída a partir das linguagens verbal e icônica, as quais se integram para representar elementos de uma cultura. Por serem simbólicas, as representações veiculadas nas narrativas dependem da capacidade representacional do artista. De acordo com Eisner (2008, p. 21), a simplificação das imagens e sua transformação em símbolos que se repetem e constituem estereótipos tornam possível que reproduções da conduta humana seja facilmente reconhecidas pelo leitor.

Sob essa perspectiva, subjacente à narrativa das histórias em quadrinhos, representações sociais são trabalhadas através dos personagens, suas ações, atitudes comportamentos e experiências; da ambientação; de situações e do desfecho das histórias. Desse modo, o que é dito e o modo como é dito é que nos permitirá identificar imaginários sociais representados nas narrativas estudadas.

\subsection{As representações sociais nos quadrinhos de Sousa}

A análise da Turma da Mônica Jovem nos permitiu identificar determinada visão sobre os papéis sociais convencionalmente atribuídos aos adolescentes, e aos seus familiares e o tipo de relação que se espera existir entre eles. Mas não é somente o ambiente familiar que é explorado. Representações da instituição escolar, da amizade, do namoro são trabalhadas nessa revista, além da infância, a qual é majoritariamente abordada na revista infantil.

As histórias em quadrinhos, produzidas dentro de um contexto sóciohistórico específico, sendo um espelho do que acontece no mundo exterior, assumem uma determinada funcionalidade nas interações reais do cotidiano. Além de expressar elaborações do sujeito produtor das revistas, essas narrativas se apresentaram também como instrumento de compreensão do mundo e de seu funcionamento. Elas podem ainda apresentar temas e assuntos sob novas perspectivas, e por isso, diferentes de concepções preconcebidas. 
Ao abordar aspectos do cotidiano de uma nova forma, o produtor das histórias contribui para dinamicidade das representações sociais, caráter imanente das mesmas, e para uma possível mudança social. No excerto a seguir, Moscovici (2007, p. 40) tece de forma clara considerações acerca desse tema.

[...] o que é importante é a natureza da mudança, através da qual as representações sociais se tornam capazes de influenciar o comportamento do indivíduo participante de uma coletividade. É dessa maneira que elas são criadas, internamente, mentalmente, pois é dessa maneira que o próprio processo coletivo penetra, como fator determinante, dentro do pensamento individual. Tais representações aparecem, pois, para nós, quase como que objetos materiais, pois eles são o produto de nossas ações e comunicações (MOSCOVICI, 2007, p. 40).

A partir desse excerto, compreendemos que o processo de comunicação possibilita a formação de novas representações sociais, as quais podem influenciar o comportamento dos indivíduos.

Constatamos com as nossas análises que uma das funções da representação da adolescência na Turma da Mônica Jovem é a de desconstruir a imagem negativa que o termo adolescente pode evocar. As representações sociais ligadas ao adolescente e comumente difundidas são relacionadas a uma fase difícil, em que ele é caracterizado como "aborrecente", malcriado, barulhento, agressivo, apático, cansativo, difícil, o que expressa uma visão preconceituosa, refletida em frases de senso comum.

Nesse sentido, as representações veiculadas nessas histórias revelam o poder de transformação da realidade social, tendo em vista que elas possuem o poder de exercer influência sobre o leitor e levá-lo a refletir e reorganizar a concepção que possui sobre si mesmo, sobre sua condição, bem como uma realidade maior que o circunda. Sobre essa capacidade de transformação, Minayo (1995, p. 90) afirma que:

[...] elas [as representações sociais] conservam sempre a marca da realidade social onde nascem, mas também possuem vida independente, produzem-se e se misturam, tendo como causas outras representações e não apenas a estrutura social (MINAYO, 1995, p. 90). 
Nesse sentido, procuramos identificar as vozes sociais presentes nas histórias analisadas e o universo de discurso que o sujeito falante deseja que o leitor compartilhe com ele. Para tanto, discutimos sobre os temas mais recorrentes nas narrativas de Sousa e as proposições apresentadas e discutidas em cada uma delas. Em nossa análise consideramos o contexto sócio-histórico em que as narrativas foram produzidas, pois ele determina tanto a produção quanto a interpretação dos enunciados.

Ao estudarmos a organização narrativa da Turma da Mônica e Turma da Mônica Jovem, descrevemos os personagens, baseando-nos em suas ações. Os papéis narrativos (CHARAUDEAU, 2009) assumidos por cada um permitiu-nos qualificá-los segundo o modo como influenciavam e ajudavam a construir os processos e funções narrativas (CHARAUDEAU, 2009). Essa estratégia nos possibilitou identificar a representação do adolescente expressa pela figura dos personagens e pelos comportamentos de cada um.

Cada um dos cinco personagens principais das revistas possui características específicas, o que contribui para diversificar e expandir a o imaginário social sobre os jovens. A Mônica, na revista infantil, era uma criança forte, corajosa, dotada de gênio forte, nervosa, mas também romântica. Na adolescência, ela ainda possui um gênio forte, mas passa a controlar melhor seus impulsos, tornando-se mais madura e segura. A Magali, amiga da Mônica desde a infância, continua meiga e delicada. Conhecida antes por ser "comilona", ela passa a se preocupar mais com sua alimentação, atitude que é consequência de uma preocupação dos adolescentes com a forma física do corpo. O Cebola, antes chamado de Cebolinha, em ambas as revistas é qualificado como esperto e inteligente. $\mathrm{Se}$, quando criança, ele desejava ser dono da rua, agora ele quer conquistar o mundo, cheio de sonhos e ao mesmo tempo de dúvidas, o que é inerente à fase em que se encontra. Desde criança ele gostava da personagem Mônica, mas, é na recente produção que o autor explora temas como namoro e apresenta uma cena do primeiro beijo dos dois. Por fim, o personagem Cascão incorpora característica do jovem "descolado", que adora praticar esportes, principalmente os radicais, como o skate. Numa tentativa de construir uma identidade própria e se identificar com um grupo, ele adota ainda um novo estilo de se vestir com a moda street.

A diferença entre os personagens não os separa. Ao contrário, ela promove um equilíbrio entre a turma e os torna ainda mais unidos. A 
valorização da amizade, tema recorrente também nas revistas infantis, é representada pela relação entre eles e se fundamenta na união, nos sentimentos verdadeiros, e no companheirismo. Em suas aventuras, eles enfrentam inúmeras dificuldades e vencem obstáculos porque sabem ajudar uns aos outros e respeitam os limites de cada um. Nesse aspecto eles se assemelham aos heróis dos mangás orientais, os Samurais. Entre as leis que compõem a código de conduta deles estão a crença na perseverança e o esforço como meio de superar obstáculos e a valorização da amizade e da união no trabalho em equipe.

A união entre a turma é reflexo também das transformações comportamentais que ocorrem na adolescência. A busca pela aceitação em mundo cheio de novas descobertas leva os jovens a procurar por identificação com aqueles que eles possuem maior afinidade, que possuem os mesmos problemas, gostos e idade. Nessa fase, o adolescente experiencia a construção de sua identidade, que é ao mesmo tempo pessoal e social e acontece de forma interativa. É na relação com o outro que cada um percebe suas semelhanças e as diferenças que os distinguem, e se tornam seres únicos.

Mas não é só o outro que interfere no desenvolvimento do adolescente. $\mathrm{O}$ espaço físico em que está inserido também exerce influência nesse processo. A descrição e o estudo do ambiente representado nas histórias em quadrinhos são estratégias que nos permitem compreender melhor o "crescimento" dos jovens e identificar informações implícitas e imaginários sociais a eles relacionados. O lugar onde os personagens são ilustrados determina em parte o tipo de comportamento que eles adotam numa certa situação. Isso acontece porque os indivíduos sociais partilham representações coletivas, as quais são resultado de várias experiências e de outros tipos de conhecimentos, transmitidos e adquiridos de diferentes formas.

No gênero quadrinhos, o estudo do espaço envolve a análise de elementos icônicos, diagramação dos quadros, a página e o próprio formato dos quadros, assim como sua disposição e o estilo empregado pelo autor. A sua representação desempenha um papel semântico no desenvolvimento da história. Ele contribui para a construção do que se chama de efeitos de clima, atmosfera e cena, e está, por isso, diretamente ligado às funções e ações dos personagens. 
A organização narrativa em lugares particulares atende às intenções discursivas do eu-enunciador e depende da capacidade do público-alvo em identificá-los e atribuir-lhes sentido com base em suas experiências e conhecimento acumulado. Argumentamos assim que subjacente às representações dos espaços físicos escolhidos, há uma expressão de valores e ideologias.

As revistas tradicionais da Turma da Mônica se estruturam de modo simples, com três ou quatro fileiras de quadros coloridos, dispostos na horizontal. $\mathrm{O}$ ambiente neles representado caracteriza-se por ser pequeno, pacato, calmo, e harmônico, onde toda a vizinhança se conhece. As construções são simples e típicas de cidades pequenas, com grandes áreas verdes e sem intensos movimentos nas ruas, o que predetermina em partes o comportamento dos indivíduos representados. Nessa atmosfera, as crianças interagem umas com as outras e se desenvolvem. Geralmente, brincam em espaços abertos e em contato com a natureza. Nessas histórias verifica-se uma idealização da infância, que se dá longe das grandes agitações dos tempos modernos.

Ao considerarmos as características do atual público-alvo dessas revistas, poderíamos pensar que os espaços representados e o que as crianças fazem nesses lugares se distancia um pouco do que realmente vivencia os leitores reais das histórias. Assim como a sociedade evolui, a infância também já não é a mesma daquela representada nos anos iniciais da revista, quando a primeira publicação da Turma da Mônica entrou em circulação. Desde muito cedo, os pais envolvem seus filhos em várias atividades diárias, como aulas de balé, de canto, de instrumentos musicais, de esportes, dentre outras, como uma tentativa de acompanhar as novas exigências sociais. Como todos os adolescentes, eles também se adéquam às novas tecnologias e delas fazem uso para se comunicar com os amigos, por meio do celular, e da internet, por exemplo, para se divertirem e até mesmo fazerem as tarefas escolares, dependendo da idade delas.

Parece haver assim, uma incongruência entre o conteúdo das histórias de Sousa e o universo infantil dos leitores. No entanto, ao pensarmos o texto como veículo de imaginários sociais, podemos entender que o eu-comunicante, através da narrativa, expressa seu posicionamento sobre o ambiente ideal e saudável para o desenvolvimento infantil, além de sugerir que a infância deve ser um tempo de as crianças se divertirem, e não se preocuparem com inúmeras responsabilidades, como fazem os 
adultos. Na sexta edição da Turma da Mônica Jovem, encontramos uma passagem que nos poderia revelar algo sobre esse modo de pensar do sujeito comunicante. Os personagens seu Sousa e D. Luísa conversam sobre a filha Mônica. O pai diz que, quando criança, a Mônica quase nunca falava sobre o que queria ser quando crescesse. A mãe concorda com ele e completa sua fala ao dizer que ela aproveitou a infância e não cresceu antes da hora.

A opção por um ambiente mais natural poderia sugerir ainda uma tentativa de aproximar os leitores da natureza, despertando-lhe um interesse por ela. Muitos dos leitores das revistas moram em grandes centros urbanos e não mantém contato direto com a natureza. Nesse sentido, a narrativa, como um instrumento de produção e disseminação de conhecimentos, seria uma fonte de informação através da qual as crianças poderiam aprender sobre uma nova realidade, diferente daquela que eles conhecem.

Não se verifica, entretanto, uma idealização bucólica do desenvolvimento infantil. Outras histórias nos mostram um posicionamento do sujeito comunicante favorável ao equilíbrio entre a natureza e os recursos oferecidos pelas novas tecnologias. Na figura 1, constatamos, a partir do contexto e do suporte dado pelas imagens, que se reconhece a praticidade que as novas tecnologias proporcionam ao homem, e que ela não se restringe apenas àqueles que vivem em grandes centros urbanos. Com a sentença “Esse povo não sabe que já inventalam o e-mail?", a personagem revela fazer uso dos recursos tecnológicos no seu dia-a-dia. Esse exemplo nos permite inferir que, embora o autor mostre as crianças em contato com a natureza, ele não demonstra ser contra a necessidade de eles fazerem uso do que as novas tecnologias lhes oferecem.

Figura 1: O uso das tecnologias

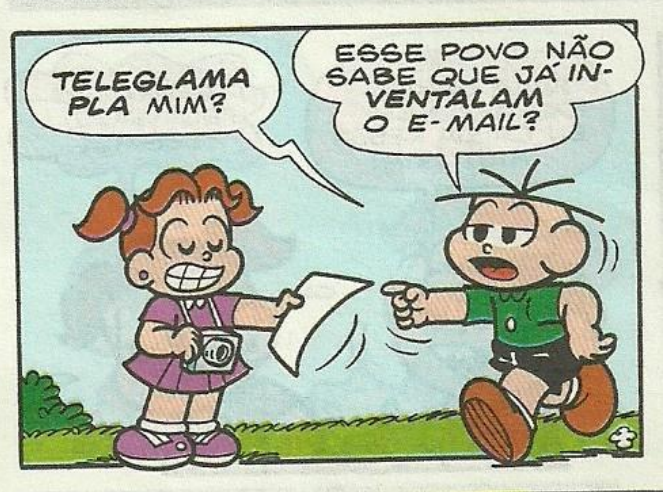


Por outro lado, em uma das histórias pudemos identificar a preocupação do enunciador com relação ao uso desses novos recursos. Indiretamente ele argumenta que os recursos tecnológicos precisam ser utilizados de forma consciente e quando realmente eles se mostram úteis e positivamente eficientes no desenvolvimento das atividades diárias das pessoas. As figuras 2 e 3 expressam uma crítica indireta à influência da televisão no desenvolvimento infantil. Em nossa cultura, o hábito de assistir à televisão tornou-se recorrente, o que na visão do enunciador contribui para as pessoas se tornarem apáticas e deixarem de pensar em coisas que são realmente importantes.

Figura 2: Tecnologias e vida infantil das crianças

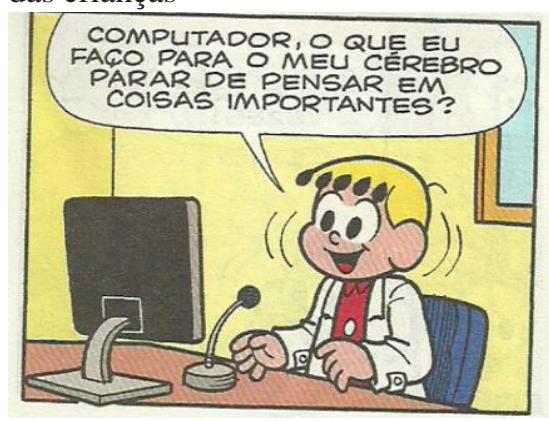

Figura 3: O uso da televisão e o desenvolvimento

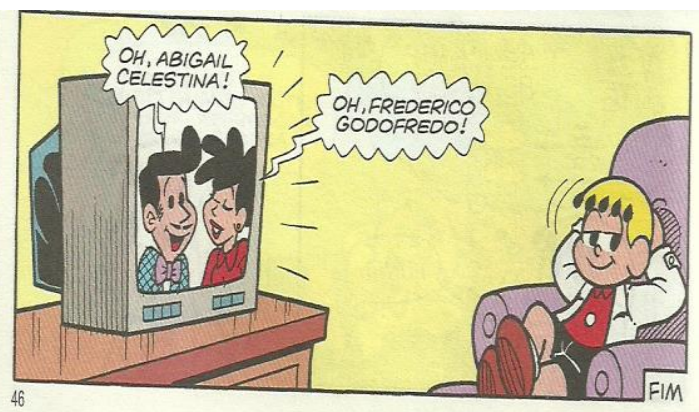

A Turma da Mônica Jovem, por sua vez, retrata o meio social e cultural onde um determinado grupo de adolescentes vive. Como uma das características da configuração das histórias em quadrinhos em estilo mangá, as narrativas dessa revista passam a explorar um maior número de locais e a detalhá-los um pouco mais. Os espaços fechados são mais recorrentes nessa produção que na anterior. Segundo Charaudeau (2008), a localização das ações num espaço fechado ou num espaço aberto, assim como a movimentação ou fixação nesse espaço, ou até mesmo o deslocamento de um para outro, são estratégias que auxiliam na produção de efeitos de cena, clima e atmosfera.

Enquanto os personagens infantis são vistos mais ao ar livre, os adolescentes são retratados dentro da escola; em casa, estudando, conversando com os amigos, ou com a mãe; dentro do shopping, fazendo compras; em salões de beleza (conferir a figura 4), e até mesmo dentro de naves espaciais, realizando viagens. $\mathrm{O}$ desenvolvimento das ações dos 
personagens nesse espaço, onde eles aparecem manipulando equipamentos modernos, como celulares e notebooks, faz com que o conteúdo da narrativa se aproxime um pouco mais da realidade dos leitores reais, retratando de forma mais aproximada o cotidiano deles. $\mathrm{O}$ grande número de transições entre esses espaços, e as sobreposições dos mesmos no requadro da página contribuem para representar o mundo jovem como um universo dinâmico, agitado e que está constantemente mudando.

Figura 4: Representação dos jovens em ambientes fechados

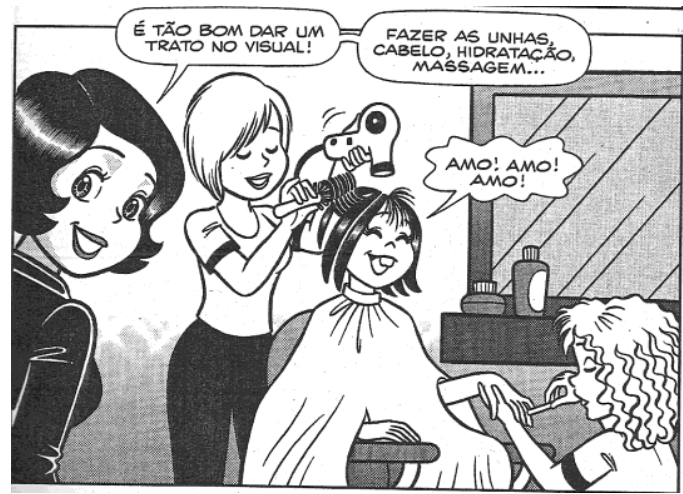

Há outros casos, entretanto, em que as aventuras dos adolescentes acontecem em dimensões mágicas, onde personagens irreais, como minotauros e monstros cefalópodes de um único olho e vários tentáculos, travam com a turma de amigos batalhas e disputam objetos e lugares. Essas passagens parecem, a princípio, se distanciar do que ocorre na vida real. No entanto, elas não deixam de constituir uma narrativa verossímil, uma vez que os temas abordados são inerentes à condição humana, como sentimentos, o convívio em grupo, as relações construídas entre os indivíduos, regras e valores que determinam comportamentos humanos em determinadas circunstâncias. O exagero do autor na representação do mundo jovem poderia ser uma de suas tentativas para conseguir chamar a atenção de seu leitor e transmitir seu modo de pensar em relação ao potencial que os jovens possuem. As vitórias dos personagens nessas dimensões representam a força que eles possuem, bem como as responsabilidades que a eles foram conferidas. Deles dependia a liberdade do Universo, que se encontrava sob ameaça da malévola rainha Yuka. 
Mais uma vez o valor da amizade é ressaltado. O conteúdo narrativo apresenta a proposta de que os amigos verdadeiros nos ajudam a superar nossas dificuldades e vencer obstáculos. A fala da personagem reforça o que é apresentado com o desencadeamento de eventos narrativos: "Nós fomos escolhidos não porque nossos pais herdaram os avatares de heróis do imperador... Nós fomos escolhidos porque sempre fomos amigos! Nossa força está em nossa união! Vamos vencer por mérito de nossas ações!!" (SOUSA, 2008, p. 126).

Além de se tornar um elemento central no desenrolar das ações dos personagens e dos eventos narrativos, a amizade é um dos temas discutidos quando D. Luísa, personagem que assume o papel de mãe da Mônica, fala sobre as "onze coisas que as garotas amam". Demonstrando conhecer bem o universo das adolescentes, ela diz que "não há nada melhor do que dividir bons momentos com suas amigas...", elas "renovam nossa energia! O que é super dez!".

Ao mesmo tempo em que o enunciador retrata questões do mundo jovem, indiretamente ele explora a relação pais e filhos e discute a função dos pais no acompanhamento do desenvolvimento de seus filhos. Ele faz isso, por exemplo, quando insere a personagem D. Luísa na narrativa para conversar com a filha e tentar ajudá-la a entender as mudanças físicas, cognitivas e psicológicas que ela estava sofrendo naquela nova fase, ou seja, na adolescência. Nesse período, ela explica, os hormônios regulam o crescimento e desenvolvimento e criam sensações que os jovens ainda não sabem controlar direito. De modo descontraído, D. Luísa explica as consequências da ação daquelas substâncias químicas e ensina regras de comportamento a Mônica e a suas amigas, como no exemplo abaixo:

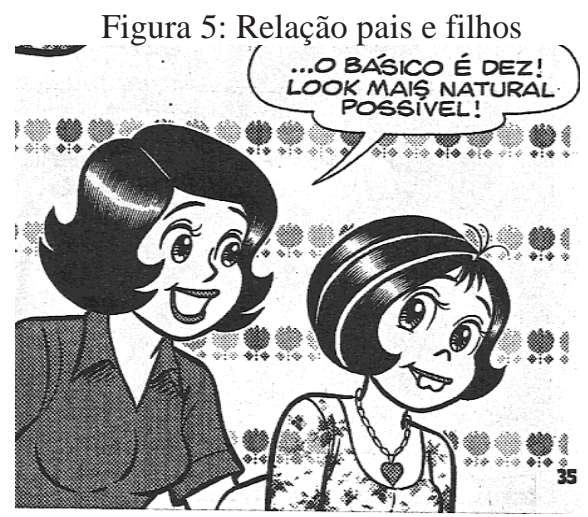

144 
Paralelamente à narrativa é construído ainda o estereótipo de família, cujos membros deveriam permanecer unidos e ajudar uns aos outros. Os episódios das sequências narrativas constroem o imaginário de que a presença da família é fundamental para o crescimento e amadurecimento saudável dos filhos, mesmo quando estes já não são mais crianças.

A preocupação com a construção de valores dos jovens transparece como outro tema nas produções de Sousa, as quais se referem à relação homem/mulher. São comuns nos noticiários da vida real casos em que as mulheres são vítimas de agressões masculinas. Como forma de influenciar e alterar a realidade, o sujeito comunicante trabalha com a valorização da ideia de que homens não devem maltratar mulheres, mas respeitá-las. Nas figuras 6 e 7 , percebemos uma transformação no modo de pensar e agir dos personagens masculinos. Antes eles queriam ficar fortes para vencer a personagem Mônica. Depois, eles se tornam atenciosos e carinhos com essa figura feminina, realizando o desejo desta de ser mais amada por eles.

Figura 6: Relação homem/ mulher

Figura 7: Tipo de relacionamento entre homes e mulheres
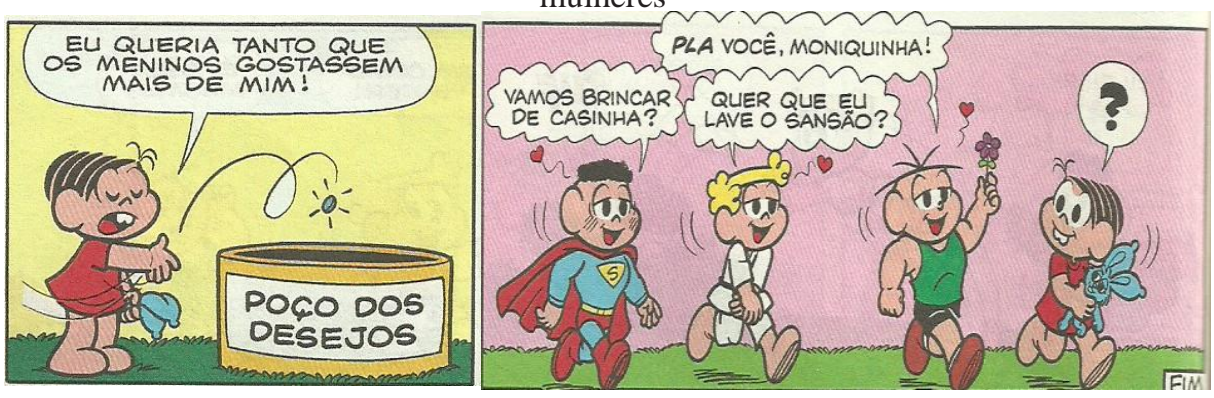

Na Turma da Mônica Jovem, é abordado outro aspecto da relação homem/mulher. Considerando que na adolescência os indivíduos começam a despertar para os romances, o enunciador procura desmistificar, ou pelo menos, amenizar a crença socialmente difundida de que "os homens são todos iguais". Adequando ao público alvo da revista, esse enunciado sofre uma pequena alteração, transformando-se em "os meninos são todos iguais". Ao pronunciar essa sentença, a personagem Denize se refere ao Titi, o qual havia terminado seu namoro com a Aninha. As garotas desconfiavam que ele planejava ir com o Cascão e o Cebola para uma "balada" no final de semana para "arranjar outra garota".

No entanto, esse não é o desfecho da história. Os rapazes haviam combinado, na verdade, de treinarem para o campeonato de beisebol. Esse final mostra às personagens, como também ao leitor real, que nem sempre 
agimos certo ao fazermos prejulgamentos com base em preconceitos sociais. O enunciador procura mostrar também que cada pessoa é única e as generalizações, por isso, nem sempre se aplicam a todos.

Ao tratar de uma fase que é nova para os sujeitos leitores que estão começando a experienciar o que é típico do mundo dos adolescentes, Maurício de Sousa emprega determinadas representações sociais que servem para agir sobre seu público. Dessa forma, além de promover entretenimento, ele contribui para a formação educacional dos leitores, construindo novas representações sociais.

\subsubsection{A reconstrução do imaginário social ligado aos jovens}

As representações, por serem produtos sociais, são dinâmicas e móveis. Ao lado da evolução de uma dada sociedade, há também uma evolução no modo de pensar dos indivíduos que a compõem. A nova forma de conceber a realidade reflete também na construção, ou reconstrução, dos imaginários sociais.

As histórias em quadrinhos, como uma das formas de mídia, contribuem tanto para veicular as representações sociais já existentes, como também para difundir novas outras. Em nosso estudo, pudemos constatar uma preocupação do sujeito comunicante com a formação de valores das crianças e dos adolescentes ao trabalhar com temas como relação familiar, relação homem/mulher, a infância e a adolescência partindo do senso comum em direção a um novo ponto de vista. É esse novo ponto de vista que o sujeito enunciante quer tornar comum entre seus leitores, numa tentativa de transformar o modo como se concebem certos aspectos de uma realidade da qual ele mesmo faz parte.

Nas produções de Sousa vemos uma preocupação com a perspectiva sob a qual o desenvolvimento infanto-juvenil é entendido. Nas histórias da Turma da Mônica Jovem, vemos, com maior recorrência, episódios que contribuem para a construção de uma nova identidade para os jovens. Como forma de desconstruir a imagem, muitas vezes negativa dos adolescentes, $o$ enunciador, por meio do narrador, organiza e constrói a narrativa de modo a destacar qualidades dos personagens e difundi-las entre seu públicoalvo. As representações sociais estão relacionadas a uma forma particular de compreender a realidade social. Caracterizar os adolescentes de 
determinadas formas é um modo de destacar determinadas características e fazer com que elas passem a caracterizar majoritariamente esse grupo social. A representação veiculada por essas histórias em quadrinhos assume assim a função de remodelar o comportamento dos jovens e ajudar os pais na educação dos mesmos.

O contexto em que as crianças e os adolescentes são representados, bem como o tipo de relação existente entre eles e os demais é um outro elemento ao qual o sujeito enunciante dá particular atenção dentro da narrativa. Uma ambientação mais favorável ao desenvolvimento dos dois grupos de pessoas influencia incisivamente no modo como eles se comportam e reagem aos fatores externos a elas. Apesar de a transição entre as diferentes fases de desenvolvimentos dos indivíduos ser um fenômeno com características físicas e psíquicas comuns à espécie, os processos que a constituem é moldado por características psicológicas e sociais culturais, sendo, por isso, marcado pela história e pela cultura de cada grupo social.

\section{Considerações finais}

Nesse estudo pudemos constatar que as histórias em quadrinhos Turma da Mônica e Turma da Mônica Jovem de Maurício de Sousa não só contam histórias, mas também são veículos por onde circulam valores, crenças e imaginários sócio-discursivos.

A partir do estudo descritivo, narrativo do nosso corpus e da análise das teses subjacentes ao conteúdo das histórias, pudemos identificar os principais personagens, qualificá-los e descrever as representações sociais a eles relacionados.

Pudemos comprovar nosso pressuposto de que as representações nos quadrinhos se constroem a partir de uma estreita relação com o que se verifica em um dado contexto histórico, social e cultural. Como um espelho, as histórias em quadrinhos, como outras produções sociais, refletem valores, crenças, normas e condições sociais, acompanhando as evoluções por que passam em diferentes campos.

Observamos também que, como instrumento de transformação social, as histórias quadrinhos analisadas trazem subjacente a sua estrutura narrativa iniciativas do sujeito enunciante para desconstruir crenças e preconceitos, os quais podem afetar a relação entre os indivíduos que convivem e interagem entre si em um mesmo espaço. Reforça-se assim que as representações sociais influenciam o modo como concebemos a realidade, e vice-versa. 


\section{Referências}

CHARAUDEAU, P. Linguagem e Discurso: Modos de Organização. São Paulo: Contexto, 2008.

DUVEEN, G. Introdução - O poder das ideias. In: MOSCOVICI, S. Representações Sociais: investigações em psicologia social. Tradução por Pedrinho A. Petrópolis: Vozes, 2007.

EISNER, W. Narrativas Gráficas. 2a ed. São Paulo: Devir, 2008.

GUARESCHI, P. e JOVCHELOVITCH, S. (org.). Textos em representações sociais. 7 ed. Petrópolis: Vozes, 2002.

JOVCHELOVITCH, S. Vivendo a vida com os outros: intersubjetividade, espaço público e representações sociais. In: GUARESCHI, P. e JOVCHELOVITCH, S. (org.). Textos em representações sociais. 7 ed. Petrópolis: Vozes, 2002.

MELO, M. S. de S. Estratégias discursivas em publicidades de televisão. 2003. 2 v. Tese (Doutorado em Estudos Linguísticos) - Universidade Federal de Minas Gerais, Minas Gerais.

- Pressupostos de uma teoria psicossocial do discurso: A semiolinguística. In: GOMES, M. C. A.; MELO, M. S. de S.; CATALDI, C. Gênero discursivo, mídia e identidade. Viçosa-MG: Ed. UFV, 2007a.

MINAYO, M. C. de S. O Conceito de representações socias dentro da sociologia clássica. In: GUARESCHI, P. e JOVCHELOVITCH, S. (org.). Textos em representações sociais. 7 ed. Petrópolis: Vozes, 2002.

MOSCOVICI, S. O fenômeno das representações sociais. In: MOSCOVICI, S. Representações Sociais: investigações em psicologia social. Tradução por Pedrinho A. Guareschi. Petrópolis: Vozes, 2007, p. 29-109.

OLIVEIRA, F. O. de e WERBA, G. C. Representações sociais. Psicologia Social Contemporânea. $12^{\mathrm{a}}$ ed. Petrópolis, RJ: Vozes, 2009.

RODRIGUES, N. N. e MELO, M. S. de S. A concepção e representação do tempo nos quadrinhos de Maurício de Sousa. Revista de Ciências Humanas, Viçosa, v. 10, n. 1, p. 158-172, jan./jun. 2010.

Recebido em: julho de 2013.

Aprovado em: agosto de 2013. 